\title{
APRENDIZAJE DE NORMAS EN LA ESCUELA: SENTIDOS Y SIGNIFICADOS DESDE UNA LECTURA MULTIESCALAR. ESTUDIO DEL CASO COLEGIO BENJAMÍN HERRERA [BOGOTÁ D.C.] *
}

Learning norms in school: senses and meanings from a multiscale perspective. The case study of Benjamin Herrera School in Bogotá D. C.

Jorge Orlando Blanco Suárez ${ }^{* *}$

Yurany Acosta Riaño***

Johanna Marcela Guzmán Pabón****

Recepción: 3 de diciembre de 2018. Aceptación: 29 de marzo de 2019.

DOI: http://dx.doi.org/10.21017/Rev.Repub.2019.v27.a72

\section{RESUMEN}

El presente texto expone los resultados de la investigación pedagógica titulada «El aprendizaje de normas en la formación política de los estudiantes», realizada en el año 2017-2018 en el Colegio Técnico Benjamín Herrera en Bogotá. La problemática indagó por los sentidos y significados que construyen los jóvenes frente a las distintas expresiones de lo normativo. Esto a partir de una perspectiva metodológica multiescalar; esto es, teniendo en cuenta los procesos de socialización en escenarios como la familia, la escuela y la sociedad en general. A partir del estudio se pueden evidenciar unos procesos de socialización en los que perspectivas autoritarias sobre la autoridad y el poder dificultan la construcción de miradas democráticas sobre lo normativo en la vida social.

Palabras clave: Aprendizaje de normas, escuela, multiescalaridad, socialización política.

* Resultado del proyecto de investigación «Socialización y formación política en instituciones educativas de Bogotá», dirigido por los profesores Jorge Orlando Blanco Suárez e Iván Ernesto Roa y desarrollado en los años 2017 y 2018.

** Docente asociado de tiempo completo. Proyecto curricular de Ciencias Sociales. Facultad de Ciencias y Educación, Universidad Distrital Francisco José de Caldas. Miembro del Grupo de Investigación Amautas: pedagogías críticas y formación de sujetos. Correo electrónico: joblancos@udistrital.edu.co

*** Licenciada en Ciencias Sociales, Universidad Distrital Francisco José de Caldas, miembro del Semillero de Investigación Grupo de Estudios Sociopolíticos, del proyecto curricular de Ciencias Sociales

**** Licenciada en Educación Básica con énfasis en Ciencias Sociales, Universidad Distrital, promotora de lectura del Ministerio de Educación Nacional. 


\begin{abstract}
The present text shows the results of the pedagogical research obtained across the development of the project «The norms learning of in the political formation of the students», realized in the year 2017-2018 in the technical school Benjamín Herrera in Bogota. The problem was about the different readings (meanings) that young people construct from different expressions of the social norm, taking into account the learning of them, which occurred in different scenarios such as family, school and society, and that are reflected in the daily use that this gives to the rules.
\end{abstract}

Key word: The learning of norms, school, political socialization, multi-scalar methodology.

\title{
INTRODUCCIÓN
}

El presente documento expone los resultados de la investigación pedagógica titulada «Procesos de socialización y formación política en colegios públicos en Bogotá». Esta investigación se desarrolló en el marco del ciclo de innovación de la Licenciatura en Educación Básica con énfasis en Ciencias Sociales, Facultad de Ciencias y Educación de la Universidad Distrital Francisco José de Caldas de Bogotá.

Dentro del marco general de indagación por los procesos de socialización política, el objetivo que orientó el presente trabajo fue identificar las lecturas que hacen los estudiantes de los grados décimo y once, del Colegio Técnico Benjamín Herrera ${ }^{1}$, frente a las distintas expresiones de las normas sociales y, específicamente, de las normas consignadas en manuales, reglamentos, estatutos, etc., en distintas escalas; en la familia, la escuela y la sociedad. De esta manera, se interpretan los procesos a partir de los cuales, los jóvenes están construyendo sus representaciones sobre las normas y su importancia en la vida social.

La estructura de nuestra exposición está dividida en cuatro apartados. Primero, se presenta la metodología bajo la cual se desarrolló la investigación, resal-

1 Ubicado en la localidad \# 16 de Puente Aranda, barrio Alcalá, en la ciudad de Bogotá. De manera específica se tomó como muestra los alumnos pertenecientes al grado 10 (2017) y 11 (parte del 2018) de la jornada mañana, que en su totalidad sumaban 100 personas. Cabe resaltar que los estudiantes se encuentran en un rango de edad de 1418 años; la mayoría, o sea un $45 \%$, es de 16 mientras que un $23 \%$ tiene 17 . Asimismo, se trabajó con 10 profesores de la institución de diferentes áreas; con algunos miembros del comité de convivencia, como el coordinador de convivencia y el docente delegado para el desarrollo de estrategias de convivencia. 
tando las perspectivas pedagógicas e investigativas y los instrumentos de recolección de información que se usaron durante el proceso investigativo. Segundo, se exponen algunas investigaciones que han trabajado los procesos de apropiación y construcción de lo normativo en la escuela y la apuesta innovadora del presente trabajo. En tercer lugar, se presentan los resultados del trabajo de investigación sobre los sentidos y significados que construyen los estudiantes frente a la norma social que les regula, organizados y analizados a partir de tres escalas: A) social, B) familiar y C) escolar. Cuarto, algunas consideraciones que surgen a partir del análisis de la información recopilada frente al aprendizaje de normas, como elemento clave para la democratización de la escuela.

\section{METODOLOGÍA}

La investigación pedagógica estuvo guiada por la construcción de una malla curricular bajo el enfoque del Aprendizaje Basado en Problemas (Torp \& Sage, 1999), cuya apuesta crítica brinda elementos para pensar en una formación política democrática (Dewey, 1998) a partir de la resignificación de la norma, al problematizar los valores que los agentes tramitan en su socialización política.

Es necesario tener en cuenta que en el transcurso de la práctica se hicieron modificaciones en planeaciones de aula, en actividades y talleres que dan cuenta de la reflexión pedagógica sobre el quehacer docente, lo cual permite plantear elementos hacia la construcción del campo pedagógico desde la práctica educativa del docente (Zuluaga \& Echeverry, 2003), reconociéndose este como intelectual portador de un saber profesional, que es capaz de ahondar y reflexionar sobre su campo de acción.

A partir de lo anterior, el análisis y la lectura de los elementos y la información recolectada se plantean teniendo en cuenta la perspectiva metodológica propuesta por Santos (1991), quien desde la cartografía simbólica presenta una forma alternativa para leer y analizar el derecho (la norma).

Según esta mirada, la norma no es una generalidad absoluta que puede ser aplicada indiscriminadamente en todo contexto. Más bien, existen múltiples formas de derecho o modos de juridicidad, que varían en cuanto a los campos de acción social o los grupos sociales que regulan. No obstante, las progresivas formas de expresión que va adquiriendo el derecho, se ven afectadas y transformadas por los modos y prácticas que se viven en las instancias inmediatamente anteriores de la norma. Así, Santos propone una mirada multiescalar sobre el derecho, con el fin de reconocer las múltiples expresiones de la norma que son objeto de socialización. En esa medida, a partir de los sentidos y significados de los estudiantes, fue posible formular y caracterizar las siguientes escalas: 
1. Escala social de la norma: Es el lugar de configuración de marcos positivos específicos para la regulación de una sociedad. Para este caso se tendrán en cuenta marcos normativos como la Constitución Política colombiana y el Código Nacional de Policía, desde los cuales se leerá la operatividad y el uso de la norma, desde la perspectiva de los estudiantes.

2. Escala familiar de la norma: Es el espacio donde se tramitan y operan prácticas, valores, costumbres y posturas frente a la norma positiva.

3. Escala educativa de la norma: Un derecho que llamaremos local, para referirnos a los usos y prácticas específicas que existen en la institución educativa frente a las normas.

Finalmente, es necesario tener en cuenta que la recolección de información fue posible gracias a diversos instrumentos como entrevistas a profesores (8), grupos focales (uno con los docentes del área de ciencias sociales y 8 con los estudiantes de grado 11), encuestas a estudiantes (100) y la aplicación de talleres y actividades pedagógicas diseñadas a través de la malla curricular propuesta; algunas de estas últimas fueron «El color de la norma», un taller sobre «El Código de Policía» y el taller \# 3 «Crónicas y distopías en relación al poder y la autoridad».

\section{ESTADO DEL ARTE}

A partir de la revisión del estado del arte, se logró identificar distintas perspectivas sobre lo normativo en la escuela, tales como el posestructuralismo, neomarxismo, y la sociología comprensiva weberiana y figuracional de Norbert Elías. En esta revisión, se pudo establecer que la mayor parte de los estudios se centran en el análisis de los manuales de convivencia, como base para la interpretación y la comprensión de nuestro problema objeto de investigación.

Así, en primer lugar, podemos hablar de una mirada posestructuralista foucaltiana, en autores como Aguilar \& Betancourt (1998), Valencia \& Mazuera, (2006), Sáenz \& Ariza (2013) y Hernández (2005), quienes han analizado el Manual de Convivencia como un dispositivo de poder constituido por un entramado complejo de imposiciones e intervenciones que opera en el interior de la institución y en la vida misma de los sujetos escolares, pero sobre todo de los estudiantes. Su intención sería inducir a los estudiantes al acatamiento de normas; es decir, corregirlos, enderezarlos, normalizarlos y hacerlos dóciles frente al poder de una autoridad jerárquica. En esta misma línea, Osorio y Rodríguez (2011) critican que el manual sea un aplicativo para corregir o «reparar» al estudiante, donde la sanción es un elemento de efectos 
personales (castigo), más que de reflexión y efectos sociales para construir comunidad.

Para este grupo de autores, las normas en la escuela se establecen como una larga lista de lo permitido y lo prohibido en el interior de la institución, pues se encuentran cargadas de imposiciones y ritualizaciones que constituyen un gobierno autoritario y vertical sobre los sujetos escolarizados. Así, el manual tiende a criminalizar y psicologizar las conductas que se han tipificado como faltas ${ }^{2}$. En este caso, dicha tipificación y su respectivo conducto regular es uno de los apartados del manual al cual se le dedica más tiempo de elaboración.

Desde esta misma perspectiva, pero centrándose en las resistencias, rebeldías e indiferencias de los estudiantes, Laverde (2015) plantea que es precisamente esta forma de operar de lo normativo en la escuela lo que conduce a una percepción negativa de la norma, puesto que esta solo es visible por medio de la sanción. Es por ello que el orden jurídico subjetivado, construido desde la experiencia frente la norma, posibilita crear un sentido de la norma como una «villana»; es decir, como algo malvado que obliga actuar y pensar de determinada manera, encerrando a los sujetos escolares en el espacio del aula con el único fin de disciplinarlos. De acuerdo con Laverde (2015), los estudiantes terminan por verse a sí mismos como actores pasivos que solo obedecen y no pueden participar en la creación de norma porque carecen de voluntad. Por ello, al naturalizar esta mirada sobre el manual los estudiantes, en algunas ocasiones, dejan como su única opción de libertad la transgresión de la norma.

En segundo lugar, Litichever (2012), desde las ideas de lo civilizatorio de Norbert Elías, afirma que la normatividad escolar pretende prescribir e intervenir en la vida del estudiante. ${ }^{3}$ La norma irrumpe para gobernar aspectos como la libertad, la performatividad estética y las identidades juveniles, el sentido de la nacionalidad, las formas en que se deben dar los procesos de aprendizaje y enseñanza, y las maneras de relacionarse con el otro (buenos modales). Asimismo, este autor problematiza la función de la norma en relación a cómo la clase social, desde el neomarxismo, es un elemento que incide en las formas de aplicación de la misma y en la definición de los sujetos sobre los cuales se aplica. En esa medida, el sentido dado a las reglas para regular la

2 En el caso de la regulación hecha por la Ley 1620/2013, se les denomina situaciones clasificadas en tipo I, II y III.

3 En el artículo 17 del Decreto 1860/1994 (reglamentario de la Ley 115/ 1994) se establecen 12 aspectos sobre la relación que los estudiantes pueden sostener con los diversos estamentos de la comunidad escolar, que se deben entrar a regular por el manual de convivencia. 
apariencia, los horarios o los procesos de aprendizaje generalmente es distinto en escuelas de estratos medios y altos frente a las escuelas de sectores populares. En las primeras, se propone "cuidar el entorno escolar», gestionar horarios flexibles y mejorar la calidad de la enseñanza; mientras en las segundas, se prohíbe hacer daños, se exige asistencia y cumplimento, además de dejar como única mirada sobre el aprendizaje la evaluación como vehículo de inserción al mundo del trabajo.

En tercer lugar, desde una perspectiva racional weberiana, incluso contractualista si se quiere, autores como Bedoya, Cano y Jaramillo (1999), la Fundación Hemisferio (2001) y en cierta medida también algunos ya enunciados como Aguilar \& Betancourt (1998) y Laverde (2015), si bien reconocen el manual como dispositivo de poder, desde sus prácticas pedagógicas buscan reconfigurar la imagen de los manuales y su construcción, estableciendo así la posibilidad de ver el Manual de Convivencia como un pacto social, donde el objetivo es la regulación de la vida en comunidad y el trabajo conjunto de las personas que conviven en la escuela, para así mediar de manera efectiva los conflictos. Desde esta mirada se propone abrir la escuela al ejercicio democrático al establecer acuerdos, consensos y disensos participativos, que definan unos mínimos de regulación frente a los derechos, las responsabilidades, las exigencias y los compromisos.

Para estos autores, asumir un pacto social en la escuela significa construir un proyecto en común (democrático) que conlleve la protección de los proyectos de vida individuales de los miembros de la comunidad escolar. Estas experiencias destacan como elementos claves para la construcción de un pacto social los siguientes: 1) la articulación, en un solo discurso, de las múltiples voces y posturas para la construcción colectiva de normas; 2) la restitución del sujeto estudiante en el espacio del aula, de manera que sea un agente activo y autónomo en la gestión escolar de los consensos sobre las normas en el aula, para que pueda pensar en «un nosotros desde un sí mismos»; 3) propiciar debates entre toda la comunidad educativa, a través de la construcción y discusión de dilemas morales, sobre temas como el concepto que se va a sumir sobre norma, cuál sería la función del manual, el tratamiento a la libertad en la escuela y la resignificación de la autoridad docente.

En síntesis, la revisión de la literatura que ha trabajado el problema de la norma en contextos escolares plantea un gran aporte en relación con las formas en que se puede asumir la norma en la escuela (Manual de Convivencia). Específicamente se proponen dos miradas. La primera concibe el manual como un dispositivo disciplinario y de poder, que se impone al estudiante para normalizar y hacerlo dócil, mediante la aplicación constante de la sanción. Así, esta es limitada a lo sancionatorio para construir el gobierno autoritario y 
vertical sobre los sujetos escolarizados. La segunda ve el manual como el producto de un pacto social en el interior de la escuela, haciendo de este un espacio democrático para la construcción colectiva de normas. Allí se tienen en cuenta las múltiples voces y discursos, la restitución activa del sujeto estudiante y la discusión democrática sobre el sentido y la operatividad de estas, a través del trabajo con dilemas morales.

Sin embargo, el problema de la norma en la escuela no puede verse como un asunto aislado de las dinámicas sociales y familiares por las cuales transitan los individuos. Todo lo contrario, la norma y su aprendizaje son resultado de un proceso complejo, inscrito en los procesos de socialización política de los sujetos, pues atraviesan la esfera social, educativa y familiar, siendo cada una de ellas un espacio de operatividad particular de la misma. Dicha complejidad también se percibe al reconocer a la escuela y sus procesos de aprendizaje sobre la norma como el espacio por excelencia donde convergen y se disputan los sentidos y significados que sobre lo normativo construyen las otras esferas en el sujeto.

Es por ello que esta investigación tiene la intención de ser un aporte metodológico y teórico que contribuya en el estudio sobre lo normativo en la escuela. En esa medida, es ineludible reconocer el carácter multiescalar de la norma a través de la perspectiva sociológica de Santos (1991), pues es necesario matizar y contextualizar su operatividad para dar cuenta de los sentidos y significados que de esta crea el sujeto; es decir, que al abordar el problema del aprendizaje de normas en el contexto escolar, deben ser tenidos en cuenta los escenarios que nutren la lectura de los estudiantes como son la familia, la sociedad y la escuela. Así mismo, el presente trabajo busca ser un aporte pedagógico hacia la resignificación de la norma como elemento democrático, que desde la perspectiva del aprendizaje basado en problemas (ABP) intenta, desde la cotidianidad, problematizar la realidad del sujeto, de manera tal que se deconstruya esa mirada punitiva de la norma, y se vea como un mecanismo de diálogo para la resolución de conflictos y de formación política en la escuela.

\section{ANÁLISIS DE RESULTADOS}

La norma, y particularmente las distintas manifestaciones de la norma positiva, como elemento constitutivo de las sociedades modernas, se edifica como, al menos discursivamente, impersonal, externa y superior a todos los sujetos, teniendo entonces un sentido universal (Weber, 2002; Bourdieu, 2005). Justamente dicho sentido se hace neurálgico a la hora de pensar en cómo el sujeto aprende e interioriza las normas, si se tiene en cuenta, como se mencionó anteriormente, que la norma no es una generalidad absoluta; por el contrario, exis- 
ten formas de derecho, como lo anunció el profesor Santos (1991), que varían según sean los campos de acción social o los grupos sociales. En otras palabras, la normatividad se socializa (y sirve para socializar a los sujetos) y opera de diferente manera, según sea el espacio vivido por los individuos que regula (la familia, la escuela y la sociedad).

En esa medida, a raíz de la investigación propuesta, se hace necesario adentrarse en las formas como los estudiantes leen, apropian y aprenden la norma en las esferas que componen su realidad (familia, escuela y sociedad). Con ello, se busca construir una lectura exploratoria acerca de las escalas normativas; de sus características, prácticas sociales, tensiones y conflictos.

De manera específica, el ejercicio investigativo hizo un acercamiento a los sentidos ${ }^{4}$ y significados que son adjudicados a cada escala por parte de los jóvenes, llegando a ver y analizar las prácticas en las cuales se desenvuelven los aprendizajes de normas de los estudiantes del Colegio Benjamín Herrera.

El primer acercamiento con los estudiantes y sus sentidos sobre lo normativo se dio a través del taller titulado «el color de la norma ${ }^{5}$, el cual permitió identificar que un $40 \%$ de los jóvenes sienten indiferencia frente a la existencia y operatividad de las normas, un $20 \%$ siente decepción, un $18 \%$ rabia, un $15 \%$ incomodidad, un 5\% miedo, y un 2\% afirmó sentir alegría. La conclusión inicial que arrojó dicha actividad es que existe un predominio de percepciones negativas frente a la norma por parte de los estudiantes.

A partir de lo anterior, es necesario interrogar ¿De dónde vienen tales percepciones en los jóvenes?; es decir, ¿Qué hace que un joven sea indiferente a las normas? Estos interrogantes nos llevan a realizar el análisis de las respectivas escalas de lo normativo, construidas desde la mirada de los estudiantes, con el fin de explicar los sentidos y significados antes mencionados frente a la nor$\mathrm{ma}$, y que se dan en el contexto de un proceso de aprendizaje.

$4 \quad$ Desde la fenomenología de Alfred Schutz (1974), la construcción de sentido parte del reconocimiento que hace el sujeto de su realidad inmediata, la cual se interpreta a partir de un esquema de referencia preestablecido socialmente. Es, por tanto, una acción propia que se nutre de los procesos intersubjetivos y está mediada por los procesos de socialización.

5 Al respecto, se trabajó a través de un conjunto colores que expresan algunas emociones así: amarillo: alegría, azul: incomodidad, rojo: rabia, blanco: indiferencia, morado: miedo, gris: decepción. Conjunto que se empleó para la resolución de las siguientes preguntas: ¿Qué me genera la existencia de la norma en el colegio?, ¿Qué siento cuando incumplo la norma?, ¿Cómo me siento cuando veo que alguien incumple la norma? 


\section{A. La norma en la escala social}

Al hablar de la norma en la escala social, particularmente de la colombiana, el lugar que han ocupado los marcos normativos positivos devela la formación de una institucionalidad política débil en la que la norma habría tenido frágil apropiación (aprendizaje) (López Alves, 2003; Camacho, 2001; Garay, 2006; González, 1994).

$\mathrm{Al}$ respecto, en el conversatorio ${ }^{6}$ sobre la constituyente de 1991 realizado con los estudiantes, se buscó reflexionar sobre la norma como construcción democrática en nuestra sociedad, a partir de la lectura de prensa de la época. Algunas ideas planteadas por los estudiantes fueron: «¿Dónde están los negros y los indígenas en las imágenes?», «lo que yo veo es que en las imágenes solo aparecen políticos», «pues yo creo que esa constitución no sirvió para nada y que todo sigue igual». En particular, un estudiante afirmó: «para mí, son los mismos con las mismas, o sea, es la politiquería que siempre ha habido, que beneficia solo a unos pocos».

En esos sentires y opiniones mostrados por los estudiantes se expresa la forma en que ellos están leyendo la política y la ley de nuestra sociedad. De este modo, algunas posturas teóricas permiten reconocer que la historia de la sociedad colombiana da cuenta de unos procesos de afianzamiento del poder por parte de unas élites políticas específicas, que les ha permitido posicionarse mejor en la estructura social, conservar y transformar las reglas de juego de manera arbitraria. Esto permite, muchas veces en contra de las clases dominadas, que la ley termine siendo un recurso privatizado que sirve para la reproducción o adquisición de más capitales en el campo social. Así, incluso el mismo Estado se transforma en un botín que capturan y se disputan los agentes y grupos sociales dominantes o que quieren llegar a serlo (Bourdieu, 1997; Foucault, 1998; Jaramillo, 1970; Bushnell, 1994; Uribe y Álvarez, 1987).

Para la actividad denominada «noticiero $c p^{7} »$, se puso en juego la percepción y la crítica que pueden construir los estudiantes frente a la información que

6 Dicha actividad, diseñada a partir de la malla curricular, consistió en el desarrollo de un conversatorio sobre el proceso político e histórico que vivió nuestro país en los años 90, conocido como La constituyente (1991). Para este trabajo se utilizaron apartes de prensa de los inicios de los 90, así como videos explicativos del periodista Jaime Garzón.

7 Esta actividad consistió en la dramatización, por grupos, de algunos hechos o noticias expuestas por los medios de comunicación, sobre la realidad política nacional. Por ello, cada grupo debía escoger una temática que fuese popular en la divulgación de los medios; por ejemplo: la implementación del nuevo Código de Policía. 
brindan los medios de comunicación, como los telenoticieros sobre la realidad política nacional. Al respecto, 5 de los 7 grupos conformados hicieron hincapié en temas relacionados con el problema de la ilegalidad y la corrupción.

Por ejemplo, un grupo expuso de la siguiente manera su noticia: «Buenas tardes amigos, parece ser que el gobierno colombiano ha confesado un nuevo delito suyo. Tenemos conocimiento de que varios jueces y fiscales han aceptado millonarios sobornos de empresas y senadores, a cambio de que les ayuden a solucionar alguno que otro problemilla con las autoridades. Estamos hablando del Cartel de la toga».

Otros estudiantes expusieron de la siguiente forma: «Es que en Colombia no para el desorden y la indisciplina de sus habitantes. Por eso se ha hecho necesario crear el nuevo código de policía, donde se dice lo que está prohibido hacer para las personas cuando están en las calles. Mientras tanto, los políticos y las empresas siguen robando plata y beneficiándose de ellas».

Con estas expresiones, los jóvenes evidencian un cierto "malestar" e inconformidad frente a algunos hechos de la política nacional, pues resaltan la constante violación de las normas, bien sea por parte de los líderes políticos como de los ciudadanos, como una manera de conseguir un beneficio personal. Por lo tanto, la norma se ha consolidado como un instrumento de uso privado, que se emplea solo cuando se puede sacar provecho de ella. Tal como diría Fajardo (2002), en Colombia la ley jurídica se acata pero no se cumple ${ }^{8}$.

Entonces, al ser la norma un instrumento de uso privado, ha permitido que ciertos grupos sociales se configuren como dominantes, en el interior de una estructura normativa corrupta, clientelista, desigual y excluyente (Fajardo, 2002; Camacho, 2001). Esto ha contribuido a que el Estado y las distintas instituciones sociales y políticas hayan sido incapaces de integrar a la sociedad en una lógica democrática de la norma, de respeto y cumplimiento a las leyes, favoreciendo la reproducción de prácticas ilegales que hacen ilegítimo el espíritu de las leyes en nuestra sociedad. De ahí el recurso permanente de la violencia y el autoritarismo por parte de distintos actores sociopolíticos que han dejado lo normativo en un reglamentarismo vacío y sin anclajes sociales efectivos (Palacio, 2003 y 2012; Pecaut, 2001).

En consecuencia, la lectura que construyen los estudiantes sobre la norma en la sociedad colombiana resalta una imagen de recurso privado e instrumental de

8 Ya en 1941, Ots Capdequi había planteado cómo desde tiempos coloniales existe un divorcio entre el derecho y el hecho, donde las prácticas sociales son contrarias del discurso expuesto por la ley (Capdequi, 1941). 
la misma; es así como se aprende la norma, lo cual dista del ideario democrático y civilista moderno de las leyes. Por ello, es común hablar de la consolidación y naturalización de prácticas de ilegalidad y corrupción que delatan la ilegitimidad del Estado y de sus leyes. Lo que ha permitido consolidar cada vez más una nación desigual y excluyente, donde «la ley es para los de ruana»; una nación en la que para los sectores populares la norma termina siendo un instrumento homogeneizador y sancionatorio del autoritarismo reinante.

\section{B. La norma en la escala familiar}

La familia como base primaria de la estructura social no está exenta de lo normativo; por el contrario, es un espacio fundamental en la configuración de hábitos relacionados con el aprendizaje de normas. En dicho escenario, el sujeto adquiere no solo formas específicas de comportamientos en términos de valores y costumbres (que, si bien no están normativizados de manera positiva, sí cuentan con estructuras propias que delimitan y configuran al sujeto) sino que también genera las condiciones para que este sea capaz de desenvolverse en esferas como la escolar y la social, las cuales cuentan con marcos normativos positivos de regulación de la acción y las relaciones sociales.

En dicho marco, las interpretaciones que los estudiantes expusieron en la encuesta realizada dentro de esta investigación muestran que frente a la pregunta \# 10 ¿cómo se está conociendo la norma en la familia? el 65\% de los estudiantes afirmaron que la reconocen cuando ellos o alguien cercano comete una infracción. Un 23\% manifiesta desinterés frente al conocimiento de la norma y tan solo un $12 \%$ evidencia un conocimiento previo de la infracción, pues conocen de antemano la norma. De esta manera, el $82 \%$ de los encuestados encuentra la sanción como la cara visible de la norma, pero al mismo tiempo, el $65 \%$ la identifica como un mecanismo instrumental que permite evadir dicho proceso sancionatorio. Al respecto cabe preguntarse: ¿Cómo se está dando la socialización de la norma en la familia, para que a la norma se le conozca mayoritariamente a través de la sanción?

Por otro lado, en el eje número 1 de la malla curricular propuesta, en la cual se planteó la pregunta ¿Por qué es importante la norma para relacionarse con otros?, se trabajó el «Código de policía», cuyo objetivo fue la identificación de los marcos normativos que regulan las relaciones sociales en espacios como la ciudad. Dicho taller fue desarrollado por medio de un conversatorio de las experiencias alrededor de los problemas de convivencia, que los estudiantes perciben en el contexto urbano. De este ejercicio, una de las conclusiones a las que se llegó fue que, en la lectura de los jóvenes, el Código entra a regular aspectos íntimos del sujeto, que trastocan los valores de las «buenas costumbres», y que 
no son aprendidas eficazmente en la familia. Al respecto, al problematizar conductas como orinarse en espacios públicos, colarse en Transmilenio, tomar en la calle, etc. algunos estudiantes afirmaron que «esas malas acciones son porque no les enseñaron en casa»; además agregaron frente a dichas acciones que «si alguien rompe la norma es problema suyo, no mío».

De esta manera, se identifica una posible crisis de los canales comunicativos de la familia, lo que es reconocido parcialmente por los estudiantes al problematizar las acciones concretas que entran a regular marcos normativos como el código de policía. Es decir que los estudiantes adjudican a la socialización en la escala familiar la responsabilidad de los problemas de sociabilidad de los sujetos, pues en esta escala no se estaría preparando al sujeto en términos de valores y estructuras de pensamiento para, como diría Simmel (2014), «la ampliación de su grupo social» ${ }^{9}$. Por esta razón, es la norma, como sanción, lo que entra a «corregir» los vacíos de sociabilidad, generando un sentimiento negativo frente a la misma, permitiendo ratificar, según uno de los profesores del Benjamín, que «Por cultura no nos gusta la norma y la costumbre es subvertirla».

Dichas problemáticas son también reconocidas por algunos educadores, quienes afirmaron que esas conductas devienen de una «disfuncionalidad familiar», caracterizada, según ellos, por presentar «una continua fragmentación en sus canales de diálogo». Esta situación, afirman docentes, «pone en cuestión, hasta los principios y valores tradicionales de la familia nuclear».

En resumen, la lectura de la norma que hacen los estudiantes, en la escala familiar, se caracteriza por presentar un sentido negativo que viene de la forma específica por la cual el sujeto conoce la norma: la sanción. Una posible explicación para ello viene de los dramas privados no resueltos por la socialización primaria que entran a ser regulados por la norma, que se hace visible en el tránsito que el sujeto hace del espacio de socialización primaria a los escenarios de socialización secundaria. Así pues, dicho problema de sociabilidad evidencia lo que docentes y estudiantes asumen como una disfuncionalidad, la cual se caracteriza por la dificultad de aprehender principios y valores tradicionales, así como también valores ciudadanos.

9 Simmel reconoce que dicha ampliación «es la aproximación de círculos sociales hasta entonces separados. Entre dos círculos $\mathrm{M}$ y N, que se diferencian radicalmente, tanto por las cualidades específicas como por la diferencia de ideas, pero cada uno consta de elementos homogéneos o estrechamente unidos, toda la ampliación cuantitativa producirá una diferenciación cada vez mayor» (2014, p. 675). 


\section{La norma en la escala escolar: Sentidos y significados desde las narrati- vas estudiantiles}

Retomando la actividad del color de la norma, en el momento de socialización de los trabajos individuales, y generalmente en la mayoría de las sesiones de trabajo, uno los elementos enunciados y que fue recurrente en la exposición de los estudiantes es que la norma, tal y como la ven, es un constructo ajeno. Para la los estudiantes, las normas son elaboradas por otros, pues afirman: «no nos preguntan», «no nos dejan participar», «no nos tienen en cuenta», «no nos consultan, porque hace parte del pacto cuando uno firma la matrícula», etc.

Respecto a lo enunciado por los estudiantes, lo que se ve es una imposibilidad, en la que el sujeto reconoce a la norma como externa y ajena (Laverde, 2015), pues como afirma un profesor del Benjamín, estos la identifican únicamente como mandatos exclusivos de los adultos. Esto pone en evidencia un problema estructural de la escuela, en tanto no ha sido capaz de integrar al sujeto estudiante a la construcción de lo público, como es el caso de las normas que regulan sus comportamientos e interacciones. De esta manera, la escuela presenta algunas limitaciones para que los estudiantes se reconozcan como agentes en la participación de lo público, pese a que esto sería parte de las competencias ciudadanas, bandera del MEN en Colombia.

Sin lugar a dudas es necesario tener en cuenta que las implicaciones que tiene la desvinculación de los estudiantes en la participación de los asuntos de regulación y control de lo colectivo permite seguir nutriendo un sentimiento que es ajeno a lo común, un ideal de sí (Mirés, 1998) ${ }^{10}$, que niega el sentido de la norma como producción colectiva.

Lo mencionado se evidenció por ejemplo en la pregunta \# 7 de la encuesta, en la que se preguntó: ¿En qué lugares sientes que tu voz es importante frente a la construcción de un entorno democrático? Un 18\% reconoció a la escuela, un $40 \%$ a la familia, un $34 \%$ a grupos de amigos y un $8 \%$ al barrio. Al respecto, puede notarse que los espacios reconocidos como más democráticos son aquellos que no tienen un marco de normas positivas, y se remite más a núcleos sociales pequeños, en donde se puede llegar a acuerdos de manera más fácil, de manera que pueden ponerse en juego aspectos concretos que satisfagan necesidades, sin que tengan necesariamente una sanción social.

10 «La entrada en sociedad» obliga al individuo a regresar a sus esquemas de percepción en la socialización primaria -ideal de yo- imposibilitándolo para asumir responsabilidades cívicas, produciéndose una desintegración social que acentúa la desintegración individual» (Mirés, 1998). 
Dichos lugares, que poseen marcos normativos positivos, dentro de su esquema de funcionamiento incluyen la sanción como parte del sistema disciplinario-socializador ${ }^{11}$. Pues es el castigo (lo visible) una de las caras más perceptibles de la norma que los estudiantes interiorizan frente al poder y la autoridad (Foucault, 2002; Deleuze, 1987), alimentando las percepciones negativas y de indiferencia frente a la norma, ya que no solo es el posicionamiento de un poder que les regula y les excluye de su participación, sino que también como aquella que corrige y sanciona aquellas acciones que no sean apropiadas para el espacio, sin considerar si estas son satisfactorias para estos.

Así mismo, por ejemplo en los grupos focales hechos con los estudiantes, a la pregunta ¿Qué características debe tener un pacto social? reconocen que un pacto democrático se caracteriza por llegar a acuerdos que satisfagan los intereses de todos. En esa medida, el posicionamiento del sujeto en la escuela hace que este dé un sentido a la norma (por ejemplo al Manual de Convivencia), en función del nivel de agrado que le puede generar, tal como lo enuncia un docente: «la satisfacción es proporcional al nivel de apropiación de la norma».

Otro elemento neurálgico durante las discusiones, los debates y los grupos focales, que complementa lo anteriormente nombrado, tiene que ver con la «libre expresión», la cual la delimita según ellos el libre desarrollo de la personalidad. Por ejemplo, a los grupos focales se les hizo la pregunta ¿Qué aspectos les molestan y cambiarían del Manual de Convivencia del colegio?; algunas afirmaciones hechas fueron: «En el manual de convivencia no se debe prohibir los accesorios y el maquillaje. Los derechos y deberes deben ser iguales para todos (profesores-estudiantes). Las clases deben ser más dinámicas. La hora de entrada debe ser a las 6:30 a. m., no antes « (Grupo focal 1101); además en otro grupo agregaron: «El manual de convivencia debe tener más opciones para portar uniforme: posibilidad de usar sacos y chaquetas para el frío, y que las niñas puedan portar pantalón. También que se regule el horario de entrada de los profesores. Y que en los baños haya papel higiénico» (Grupo focal 1103).

Dichas demandas en su mayoría se recogen en aspectos que por lo general son los que más se sancionan en la escuela: los conflictos por uniformes, accesorios, etc. Como afirma un profesor del Benjamín, este tipo de conflictos por los parámetros estéticos son «pan de cada día» en el colegio. Es decir que por ser

11 El sistema disciplinario-socializador, como sistema, no opera solo como sanción, también con incentivos, precisamente, pues está orientado a que la coacción externa se vuelva coacción interna. Si opera solo la sanción, entonces no es racional; no se logra la «dominación racional» sino el mero autoritarismo; normas sin sentido que se instalan, desde afuera, pero que no se incorporan. 
estas las acciones que más demandas tienen a lo normativo en el colegio, es la sanción que regula dichas acciones la cara más visible de la norma, de manera que pone en disputa ese sentido de la «libre expresión» o satisfacción que desea el estudiante, generando así una molestia con la norma y aquellos que la crean para perjudicar.

En dicho marco, desde la actividad «crónicas y distopías» ${ }^{12}$, se hace evidente un «espíritu de venganza» (Nietzsche, 2011) ${ }^{13}$ por parte de los estudiantes, en respuesta a la autoridad que ejerce la sanción sobre ellos; ello visto por medio de las narraciones que se hicieron frente a sus visiones sobre la autoridad y la posibilidad de tener el poder y el control para regular el espacio como la escuela. Así las cosas, lo que se pudo hallar en términos generales es que los estudiantes enarbolan la bandera de la justicia de las tarántulas, pues buscan a partir del castigo redimir su estado de dominados.

Algunas expresiones que manifiestan esta tendencia fueron: «Frente a una orden del profesor, los estudiantes no quisieron obedecer y lo lincharon, y entonces los profesores temían por su vida» (Distopía, 1004); «Dónde se quiere matar a todos los que, en un momento, tenían el poder (coordinadores y profesorado)» (Crónica,1002), o «Una multitud armada de estudiantes busca venganza (Distopía, 1002); «Una rebelión contra el manual de convivencia» (Crónica, 1002).

$\mathrm{Al}$ respecto un profesor enuncia que lo que sucede en la escuela es que se «han normalizado prácticas simbólicas sutiles como la agresión o la violencia»; otro docente agregó también que «los estudiantes son a veces más autoritarios que el mismo profesor, y no se dan cuenta de ello». Es decir, que las anteriores expresiones dan cuenta de la institucionalización de la violencia simbólica, desde la cual el dominado (el estudiante) reproduce y legitima las estrategias asimétricas de poder y control de manera no consciente (Bourdieu, 2000). Así, los estudiantes manifiestan que "Quien tiene el poder lo aplica y punto. Entonces frente alguna discusión, quien es superior aplica el castigo y falta al respeto» (Crónica, 1004).

12 Dicha actividad consistió en la creación de crónicas, desde las cuales se hiciera visible una situación problema en el colegio, que tuvieran los estudiantes con alguien; la única condición fue que la historia se tenía que contar desde la postura del otro. Y las distopías buscaban reconocer ¿cómo sería un colegio sin normas? y lo narran por medio de un escrito.

13 Al respecto, en el discurso «de las tarántulas» del libro Así habló Zaratustra, Nietzsche expresa cómo aquellos predicadores de la doctrina de la vida son, en el fondo, tarántulas que detrás de su discurso sobre la justicia predican sobre el castigo y la muerte: "vuestra venganza destaque detrás de vuestra palabra "justicia" (Nietzsche, 2011). De tal manera, que se alimenta el deseo de hacer daño a quienes ostentan un poder, el cual posiciona como dominado al que desea. 
Esto permite ver que las referencias sobre el poder, la autoridad y las normas que vienen del núcleo familiar, social y escolar están formando un sujeto individualista y autoritario ${ }^{14}$, puesto que a partir de prácticas de exclusión y el predominio de prácticas sancionatorias permite que sea únicamente a través de la violencia como se conozca y se haga partícipe de la norma; resultado de ello, lo que en realidad se estaría formando es estudiantes que reproducen y legitiman en algún nivel el mecanismo de autoritarismo como representación de la ley.

Por la forma como la escuela se presenta a sí misma y a la norma, se «generan estados de insatisfacción y vacío, dolor, desdicha, descontento y malestar» (Elías, 1990, p. 153). A través de los grupos focales se intentó brindar el espacio para que estos se sintieran parte de la posibilidad de cambio de la norma en la escuela. Por ejemplo frente a la pregunta de la encuesta ¿Qué tan participativo te consideras para?:1) crear propuestas que reformen el manual, frente a temas que te generan inconformidad y 2) pactar normas de convivencia para tu grupo, un $20 \%$ de los estudiantes manifestaron ser participativos frente a la creación de normas y de reformas, mientras un 52\% manifestó no serlo, y además no interesarse por ello.

Lo anterior presenta aspectos encaminados al desarrollo de actitudes de desinterés por parte de los estudiantes, quienes a pesar de cuestionar el poder y la autoridad en la escuela, les genera indiferencia hacerse partícipes de los espacios. Ejemplo de ello fue que durante el desarrollo de los grupos focales, el $30 \%$ se mostró interesado y participativo mientras el $70 \%$ restante mostró pasividad, delegando su posibilidad de opinar a los estudiantes que participan regularmente o a quienes consideran que «saben más» 15 , como una forma de autoexclusión o anulación frente a la plenaria, que en últimas terminan legitimando el autoritarismo de nuevo, como cara del poder.

En respuesta al desinterés y el rechazo frente a lo normativo por parte de los estudiantes en el colegio, a través del taller de «construcción de crónicas y

14 «Solo el individualista, esto es, quien ha perdido su identidad, disociándose respecto a los demás, puede caer en la masa, disolviéndose en la cultura y transformándose, en una personalidad adaptada y obediente a los mandatos que provienen de la sociedad. La masificación que resulta del aislamiento individualista favorece notablemente la manipulación de la personalidad por mecanismos de producción y de consumo y, lo que es peor, deja abiertas posibilidades a la "tentación totalitaria” (Mirés, 1998, p. 195).

15 Lo que se ve en estos estudiantes es que son aquellos que académicamente son más productivos, reflexivos y críticos; podría decirse que su habitus les permite el posicionamiento en un mercado de bienes simbólicos que ponen en juego el papel del sujeto dentro del campo (Bourdieu, 1995) tal que este limita y anula al sujeto si no posee un capital considerable para competir por su posicionamiento en la toma de decisiones dentro del aula. 
distopías», fue posible identificar la heteronomía y el reglamentarismo como expresión del autoritarismo desde el cual se les ha socializado, pues en varias de las narrativas creadas por los estudiantes, frente a la posibilidad distópica de ver un colegio sin normas, la única solución que planteaban eran normas creadas y aplicadas por docentes y directivos, nunca como una iniciativa de ellos; es decir, la necesidad de una regulación impuesta por alguien superior, que les indique lo prohibido y lo permitido en el contexto escolar.

Un ejemplo de lo anterior es una de las distopías escrita por un estudiante, en la que llega a plantear que frente a la ausencia de normas en el colegio: «...los estudiantes se mataban entre sí, tenían sexo en cualquier parte, fumaban marihuana, etc. Pero un día un profesor dijo ya no más y comenzó a hacer las reglas que debían seguir todos los estudiantes» (Distopía, 1003). Y otro agregó que «Al pasar el tiempo, los estudiantes se iban y se iban porque el colegio era un caos sin normas, hasta que el colegio quedó con muy pocos estudiantes, y el coordinador se dio cuenta de esto, entonces decidió poner normas y hacerlas cumplir para hacer un colegio de bien» (Distopía, 1004).

Respecto a lo anterior, cabe resaltar que ninguno de los escritos presentó como posibilidad a la solución del caos, un acuerdo entre estudiantes, o entre estudiantes y directivos; la totalidad de los escritos resolvieron, como ya se mencionaba, por la imposición de normas por parte de uno de los agentes educativos que poseen autoridad. Otro elemento a considerar es que hubo una tendencia a reconocer que la existencia de normas en el espacio generaba mejores acciones en términos de valores, como por ejemplo respeto, tolerancia, etc. Frente a ello es necesario volver al escenario familiar, y las dificultades que este presenta, y considerar: ¿Es posible pensar que el aprendizaje de normas pueda servir de base para la construcción de valores colectivos? Esto pues, como se ha narrado en el presente documento parece ser que los valores que se están socializando no son precisamente los democráticos, por el contrario, son aquellos encaminados a la legitimación del autoritarismo, la heteronomía, la violencia, como únicas formas de aprendizaje de normas.

\section{CONCLUSIONES}

El proceso de aprendizaje de normas permite el posicionamiento del sujeto frente al poder y la autoridad. Sin embargo, dicho proceso se complejiza, si se tiene en cuenta que este no solo hace parte de la socialización política en la escuela, sino que también se alimenta de la experiencia que le brindan otros escenarios como la familia o la sociedad.

En esa medida, a través de esta investigación pedagógica, los aspectos problematizados frente al aprendizaje de normas permitieron reconocer, des- 
de la lectura hecha por los estudiantes, que las referencias sobre el poder, la autoridad y las normas que vienen del núcleo familiar, social y escolar están formando un sujeto individualista y autoritario, debido al predominio de prácticas de exclusión y de sanción que les limitan su participación en la construcción colectiva de normas.

Lo descrito anteriormente ha permitido que se forjen sentimientos negativos que permean los significados de la norma que hacen los estudiantes. Por tal motivo, las prácticas sociales asumidas por estos operan en torno al uso instrumental que pueda hacérsele a la norma para beneficio propio, evidenciando que el sujeto está inmerso en la ética de los máximos; tal que exige que la realidad se adapte a sus deseos, lo cual es imposible, pues los objetos de esa realidad son también sujetos, y no solo objetos a disposición de la voluntad narcisa.

Entonces, las relaciones y prácticas sociales creadas por el sujeto individualista impiden el desarrollo de una sociedad democrática, que reconozca en las normas una posibilidad de bienestar colectivo. En esa medida, es necesario generar procesos de resignificación de las normas en espacios como la escuela, siendo este el espacio por excelencia de socialización política. Entonces algunos aspectos a tener en cuenta, como parte de la formación democrática de la escuela, son:

1. Considerar la multiescalaridad de la norma (Santos, 1991), en la medida en que no puede ejecutarse una norma general, externa y ajena a la particularidad de cada contexto escolar. Entonces es pertinente comprender lo particular del espacio y sus prácticas; es decir, reconocer las necesidades, las problemáticas y las potencialidades como insumos verdaderos para la construcción de las normas, por ejemplo el manual de convivencia.

Una acción concreta puede ser la identificación de estos elementos mediante un trabajo de caracterización, que implique la descripción y el análisis de las prácticas y discursos que habitan el escenario escolar particular, de manera tal que se hagan evidentes las verdaderas problemáticas que deben ser tratadas por lo normativo. Con lo cual, desde el trabajo de estudiantes, profesores y directivos se construyan críticamente los anclajes sociales que la norma en la escuela requiere para que sea un verdadero pacto social democrático.

2. Pensarse en la construcción de un pacto colectivo que dé apertura a la democratización de la escuela, centrándose en el fortalecimiento de los procesos de construcción de identidad y sentido de pertenencia hacia la comunidad educativa; tal que permita la participación plena de todos los agentes escolares, eliminando así las prácticas sociales individualistas que han limitado las acciones democráticas en la escuela. 
Así mismo, transformar el sentido que se viene socializando sobre la norma; es decir, dejar de lado la sanción como la única cara visible de la misma, para así reconocerla como un elemento liberador y protector de la comunidad educativa, que va más allá del castigo.

Sin embargo, la norma no puede desligarse de la sanción, puesto que es necesario reevaluar la finalidad que tiene esta, como un elemento complementario. Es decir, en el marco del aprendizaje de normas, la sanción debe posicionarse como un aspecto de reflexión, que le permita al sujeto reconocer que sus acciones afectan el bienestar de sí mismo y de los demás, retomando así el deber ser democrático la norma.

Finalmente, considerar la democratización en la escuela es un proceso de largo aliento, pero muy importante si se quieren lograr transformaciones sociales, pues es el primer lugar, en el cual el sujeto puede posicionarse políticamente frente al poder y la autoridad. Así mismo, es el espacio desde el cual se puede tejer resignificaciones frente al sentido de la norma, asegurando un camino hacia la defensa de la democracia.

\section{REFERENCIAS}

Aguilar, F y Betancourt, J. (1998). Procesos de construcción de cultura democrática en Instituciones educativas de Santa Fe de Bogotá. IDEP-CEPECS, Bogotá.

Bedoya, Cano y Jaramillo. (1999). «Los manuales de convivencia escolar en la educación oficial de Antioquia». Revista Educación y Pedagogía, vol. 16 (38), pp. 141-146.

Benedicto, J. (1995) «La construcción de los universos políticos de los ciudadanos», en Benedicto, J., y Morán, M. L., Sociedad y Política. Temas de sociología política, Editorial Alianza, Madrid, pp. 227-268.

Bourdieu, P. (1995). La reglas del arte: Génesis y estructura del campo literario. Editorial Anagrama. Barcelona.

Bourdieu, P. (1997). Razones prácticas sobre la teoría de la acción. Editorial Anagrama. Barcelona.

Bourdieu, P. (1999). Campo del poder, campo intelectual y Habitus de clase. En Pierre Bourdieu, Intelectuales política y poder, Editorial Universidad de Buenos Aires, pp. 23-42. 
Bourdieu, P. (2005). «El misterio del ministerio. De las voluntades particulares a la voluntad general», en Wacquand (Coord.), El misterio del ministerio, Editorial Gedisa, Barcelona, pp. 71-80.

Bushnell, D. (1994). Colombia una nación a pesar de símisma: de los tiempos precolombinos a nuestros días. Editorial Planeta Colombiana S. A.

Camacho G., A. (2001). «Democracia, exclusión social y construcción de lo público en Colombia». En Valencia, A., (Ed.), Exclusión social y construcción de lo público en Colombia. Universidad del Valle, Cali.

Capdequi, OTS (1941). El Estado Español en las Indias. Fondo de Cultura Económica, México.

Deleuze, G. (1987). La imagen-tiempo: estudios sobre cine 2. Editorial Paidós, Barcelona

Dewey, J. (1998). Democracia y educación: una introducción a la filosofía de la educación. Madrid: Morata

Durkheim, E. (1985). Las reglas del método sociológico. Fondo de Cultura Económica. México.

Elías, N. (1987). El proceso de la civilización. Fondo de Cultura Económica. (1990). La sociedad de los individuos. Barcelona: Península.

Fajardo, L. (2002, junio 12). «La corrupción heredada: pasado colonial, sistema legal y desarrollo económico en Colombia». Revista de estudios sociales Universidad de los Andes, (12), pp. 22-30.

Foucault, M. (1998). Vigilar y castigar. El nacimiento de la prisión. Siglo XXI Editores. México DF.

Fundación Hemisferio (2001). El manual de convivencia como pacto social: una estrategia sistemática para su construcción en forma democrática y participativa (informe final). IDEP, Bogotá.

Funes, M. (2016). «Socialización política y participación ciudadana. Jóvenes en Dictadura y Jóvenes en Democracia». Revista Estudios de juventud, Universidad de Educación a Distancia, pp. 57-76.

Garay, L. (2006). Colombia: Diálogo pendiente. A propósito del Estado social del derecho en Colombia. Editorial Planeta. Bogotá. 
González, Fernán E. (1994). «Soberanía popular y crisis del bipartidismo: Entre la política tradicional y la política moderna». En JURSICH DURÁN, Mario (Editor), Soberanía popular y democracia en Colombia. Ediciones Foro Nacional por Colombia. Corporación SOS Colombia. Bogotá, pp. 140-191.

Hernández, G. (2005). La imagen de convivencia en el manual de convivencia del colegio de bachillerato comercial «Alfonso Arango Toro» (tesis de maestría). Universidad Javeriana, Facultad de Educación, Bogotá.

Jaramillo, J. (1970). Algunos aspectos de la personalidad histórica de Colombia. Revista de la Universidad Nacional (1944-1992), (7), pp. 57-75.

Laverde, G. (2015). La norma en la gestión escolar, dispositivo para restituir al sujeto (Tesis de maestría). Universidad de Manizales, Facultad de Ciencias Sociales y Humanas, Bogotá.

Litichever, L. (2012). «¿Qué se regula hoy en las escuelas?: Una mirada sobre las prescripciones de los reglamentos de convivencia». Revista Iberoamericana de Educación, 1-10.

López-Alves, F. (2003). La formación del Estado y la democracia en América Latina. Editorial Norma.

Marcuse, H. (1979). El hombre unidimensional. Planeta-Agostini, Buenos Aires.

Mirés, F. (1998). El malestar de la barbarie. Erotismo y cultura en la formación de la sociedad política, Editorial Nueva Sociedad, Caracas-Buenos Aires: Libros de la Araucana.

Nietzsche, F. (2011). Así habló Zaratustra. Un libro para todos y para nadie. Editorial Gredos.

Osorio \& Rodríguez. (2011). «Análisis de los manuales de convivencia de las instituciones de educación media en Bogotá. Un Estudio de caso». Revista RIIEP, vol. 5 (1), 79-92.

Palacio, M. (2003), Entre la legitimidad y la violencia. Colombia, 1875-1994, Editorial Norma, Bogotá

Palacio, M. (2012), Violencia pública en Colombia, 1958-2010, Fondo de Cultura Económica, Bogotá

Parsons, Talcott (1996). El sistema social. Traducción de José Jiménez Blanco y José Cazorla Pérez. Ediciones de la Revista de Occidente. Madrid. 
Pecaut, D. (2001), Orden y Violencia. Evolución sociopolítica de Colombia entre 1930 y 1953, Editorial Norma, Bogotá

Rodríguez, A. (2000). «El maestro, ¿un operador de refuerzo, un administrador de currículo o un profesional de la pedagogía?». En Antonio Luis Cárdenas, Abel Rodríguez, Rosa María Torres, El maestro protagonista del cambio educativo, Editorial Magisterio, Bogotá, pp. 101-110.

Sáenz \& Ariza. (2013). «Los manuales de convivencia escolar como dispositivos de gobierno». En Olga Restrepo (ed.), Ensamblando heteroglosias. Universidad Nacional de Colombia, Bogotá.

Schütz, A. (1974a). El problema de la realidad social. Amorrortu, Buenos Aires.

Santos, B. (1991). Una cartografía simbólica de las representaciones sociales. Prolegómenos a una concepción posmoderna del derecho. Revista Nueva Sociedad, No. 116, pp. 18-38.

Simmel, G. (2014), Sociología: estudios sobre las formas de socialización, Fondo de Cultura Económica, México, DF.

Torp \& Sage. (1999). El aprendizaje basado en problemas: desde el jardín de infantes hasta el final de la educación secundaria. Amorrortu Editores, Buenos Aires.

Uribe de H., M. T., y Álvarez, J. M. (1987). Poderes y regiones: problemas en la constitución de la nación colombiana 1810-1850. Departamento de Publicaciones de la Universidad de Antioquia, Medellín, Colombia.

Valencia \& Mazuera, V. (2006). «La figura del manual de convivencia en la vida escolar: elementos para su comprensión». Revista científica Guillermo de Ockham, vol. 4(1), 119-131.

Weber, M. (2002). Economía y sociedad. Esbozo de una sociología comprensiva, Fondo de Cultura Económica, México.

Zuluaga \& Echeverry (2003). «El campo intelectual de la educación y el campo pedagógico: posibilidades, complementos y diferencias», en Zuluaga et al., Pedagogía y Epistemología, Grupo Historia de la práctica pedagógica. Editorial Magisterio, Bogotá. 